\title{
Eventological modeling of housing and communal services system
}

\author{
Sergey Amelchugov ${ }^{1}$, Alexey Klimov ${ }^{1 *}$, Oksana Mickevich ${ }^{1}$, Olesya Nikitina $^{1}$ \\ ${ }^{1}$ Siberian Federal University, Pr. Svobodny 82, Krasnoyarsk, 660041, Russian Federation
}

\begin{abstract}
Results of eventological [1] modeling of housing and communal services system $[2,3,4,5,6,7,8]$ are looked at in examples and illustrations, which are intended to demonstrate the main features of the evaluation of activities under the circumstances of the event on the basis of a portfolio of identification features of housing and communal services; in addition, these examples and illustrations show the role and functions in the risk assessment of the three main event-related figures involved in the eventological system of housing and communal services: the total subject, the total object and the total barrier, and, most importantly, discover the key applicability of the eventological approach in the field of housing and communal services in the methods of selecting the optimal portfolio of identification features of housing and communal services, providing a given accuracy of efficiency assessment in the settlement at a given minimum expert costs.
\end{abstract}

\section{Eventology of housing and communal services}

Recently $[2,10]$ a new world-view in the field of housing and communal services (HCS) [2, 10] has been proposed, which is determined with respect to the subject, events, probability and value.

\subsection{Subject, event, probability, and value}

Only the subject (or a set of subjects) puts sense in the concept of efficiency of housing and communal services that defines and characterizes discomfort. Without a subject, the concept of efficiency of housing and communal services is devoid of any meaning.

It has long been observed and repeatedly stated [1] that the subject does not exist without events. The event is the being of the subject, the subject being, the event, and only in the event the individual realizes its existence.

In eventology [1] every event has its probability, and the concept of probability does not make sense until the event in question is defined. Thus, the event does not exist without probability, as the probability does not exist without the event. The second inherent subjective characteristic of the events in eventology is its value.

Each such set of events occurs in the form of a particular situation, a particular set of

\footnotetext{
*Corresponding author: klimovas_2011@mail.ru
} 
circumstances, a combination of the occurrence or non-occurrence of events from this set, a terraced event created by this set.

Here we are interested in those aspects of the subject's existence, those sets of events, together with their $Э$ - distributions, which give rise to his discomfort or his lack of discomfort. It goes without saying that subjective discomfort and subjective lack of discomfort are relative categories defined with respect to the set of events that the subject chooses each time.

Conclusions of the subject of the presence of the efficiency of housing and communal services in the current set of circumstances is always preceded by a conscious or unconscious assessment by the subject of the probability and value of causing or not causing damage to the subject by this coincidence of circumstances - the subject's assessment of the probability and value of this terraced event. Thus, both discomfort and comfort are not only subjective and relative, but also probabilistic and value categories.

Following [2] and [3] it is appropriate to emphasize the important idea, revealing eventological understanding of housing and communal services and insurance:

- Both comfort and insurance are always subject side and subject insurance, measured mathematically on the basis of the eventological model of the subject and subject methods of accounting and management of probabilistic and value eventological distributions of sets of events in the field of housing and communal services and insurance.

It is proposed in $[3,11]$ to use the methods of ontological modeling of housing and communal services systems in the framework of eventological system analysis, the result of which is the eventological model of housing and communal services settlement.

\subsection{Eventological system of housing and communal services}

In paper [3] the mathematical models of housing and communal services systems ${ }^{4}$ are proposed on the basis of the eventological theory of systems [1] and the last developments in the field of housing and communal services eventology [2]. Housing and communal services systems exist in every corner of the world, in each settlement.

To express eventologically, to explain and measure the HCS systems as an event system, we must first agree what to define in eventology by the event system and, in particular, to differentiate the concept of system events from still central to this theory concept of a set of events.

In eventology mathematical models of the HCS systems are considered within the framework of the eventological theory of systems (eventological system analysis) [1]. Starting from our paper [13], it is proposed to understand the eventological system (event system) as a set of events that consists of a free set of events (system basis) and events that are operationally related to events from the basis (system shell) [17-22].

\section{Glossary of concepts and tasks of applicable HCS eventology}

The Gibbs eventological model of the HCS settlement system is an eventological model describing the event-based behavior of three total HCS figurants: the subject, barrier, the object, and evaluating probability of the settlement event by the results of the expert examination of the event state of the HCS company, carried out in the framework of the expert portfolio of I-signs.

Identification of the regulatory parameters of the Gibbs event model-maximum, average and minimum risks (HCS probability service) - for this enterprise by the set of historical, expert and model statistics (see paragraph 4.3).

"I-sign" is an identification HCS sign of this enterprise, which values assessed by the expert determine the performance/failure to comply with regulatory HCS requirements; a 
synonym for "I" event - is an ID HCS event for this enterprise, the occurrence of which characterizes the execution of regulatory HCS requirements, evaluated by the expert;

"I-signs" portfolio is a set of И-signs of A used in the eventological HCS model to assess the probability of events in this HCS area.

The figurant portfolio of "I-signs" is one of three subsets of I - signs characterizing each of three figurants involved separately: total subject, total service and total object, and used in eventological HCS model for the assessment of probability of the HCS service for the corresponding person involved (subject: $\mathrm{M}$, barrier: B, object: X).

The internal figurant sub-portfolio of "I-signs" is one of two subsets of "I - signs" characterizing two-multiple state of each of three figurants involved: the total subject, total service and total object, and used in the HCS eventological model for the corresponding figurant involved (internal subject: Mi, M2, internal barrier: Bi, B2, internal object: Xi, X2).

An average probable portfolio of "I-signs" is the portfolio A, which approximates portfolio of I-signs in average meaning and composed of average probable I-signs, each of which approximates on average one of sub-portfolio of A portfolio, respectively.

An expert portfolio of "I-signs" - is a set of I-signs ща $\mathrm{A}^{(\mathrm{e})}$, selected from the general portfolio of I-signs of $\mathrm{A}$ and proposed for expert verification of the HCS level of the enterprise; similarly defined are expert figurant portfolios and internal sub-portfolios.

The minimum expert portfolio of "I-signs" is an expert portfolio in which each I-sign belongs to only one of the six sub - portfolios and each of the six sub-portfolios contains only one I-sign.

A weighted minimum expert portfolio of "I-signs" is an expert portfolio in which each I - sign belongs to only one of the six sub-portfolios, and each of the six sub-portfolios contains at least one I-sign.

Assessment of the I-sign portfolio weight (based on the statistics of expert surveys and on the basis of the Gibbs model, from which follows the log dependence of the portfolio weight of the I-sign on the probability of its values), characterizes its impact on the risk (probability) of the HCS among other I-signs of the portfolio (see paragraph 4.5).

Assessment of information capacity of I -sign in the portfolio (based on the statistics of expert surveys and evaluation of information obtained when checking its value), characterizes the information importance of expert verification of the value of this feature.

Assessment of the accuracy of risk calculation (the HCS utility probability) at the enterprise and its dependence on the number of I-signs in the expert portfolio see in paragraph 4.6 .

An optimal export portfolio of I - signs for a given enterprise is the portfolio of I-signs A (e)(\$), which provides a given level of risk assessment accuracy (probability of the HCS utility ) at minimum expert costs (see paragraph 4.5). 


\section{Event hierarchy of the HCS eventological system in pictures}

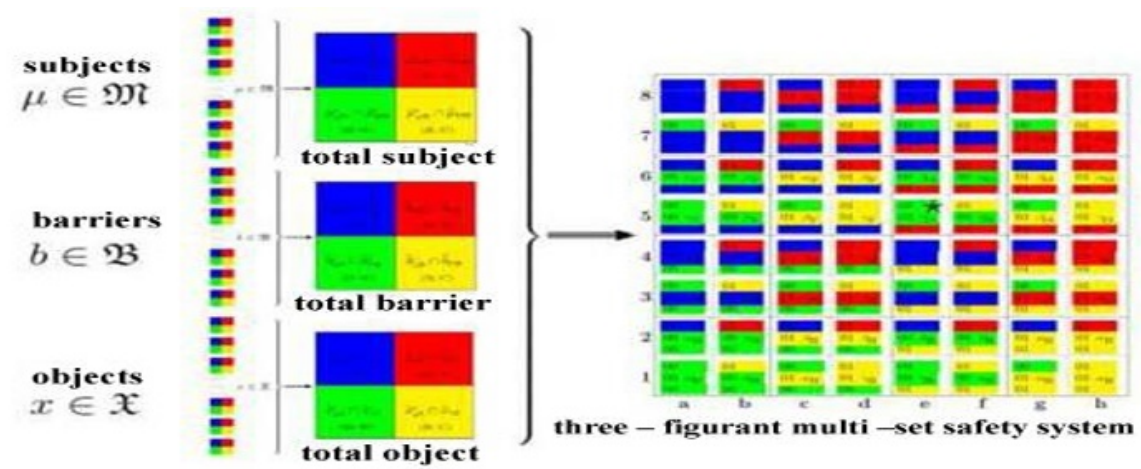

Figure 1. The event hierarchy of the eventological security system consists of three levels - the left: a set of subjects M, a set of services B and a set of objects X; the middle: three system figurants involved; the right: three-figurant eventological security system.

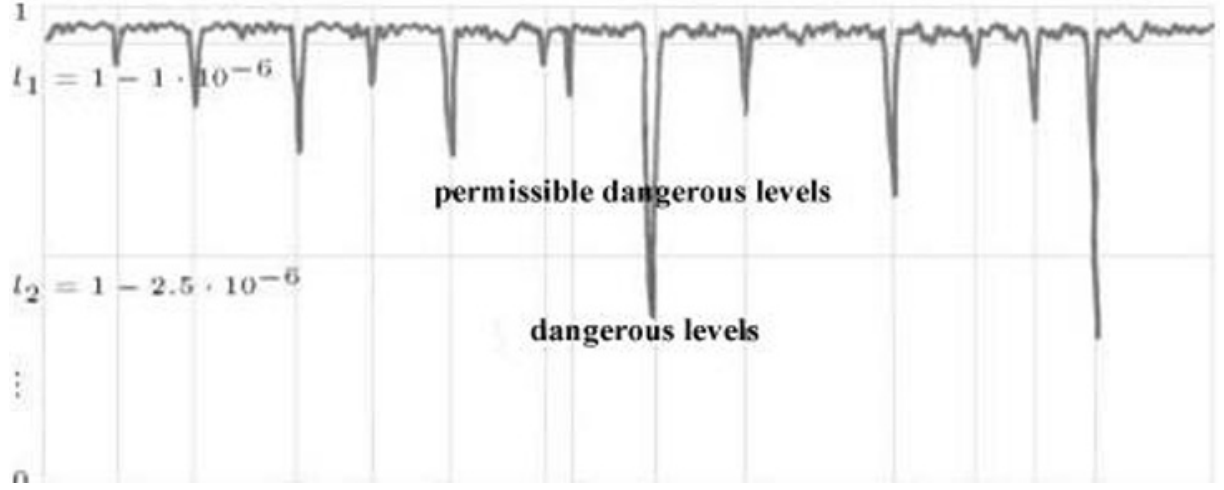

Figure 2. Trajectory of services. Graph of probability of safety $0<\mathrm{L}<1$ (vertical axis on a nonlinear scale) for the approximate 50-year sequence of 13 hyper cycles of the HCS system. The frequency of events is 0.04 ( 2 events in 50 years). levels: li $<1<1$; acceptable levels: $12<1<11$; invalid levels: $0<1<\mathrm{L} 2$.

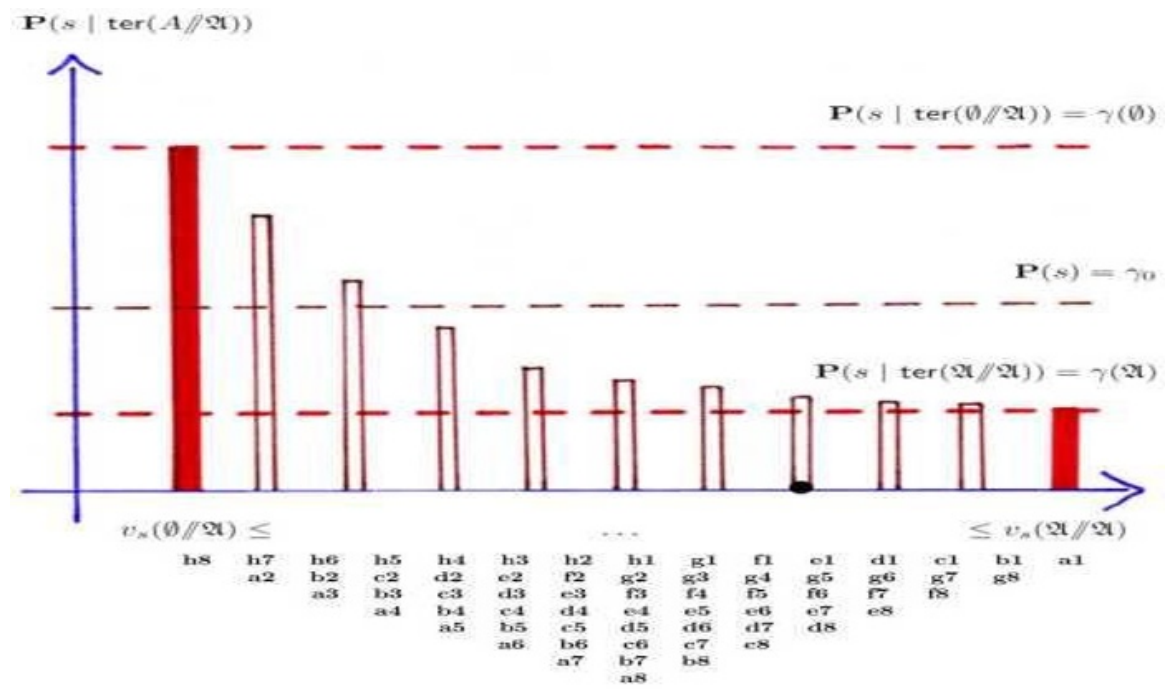

Figure 3. Model of Gibbs risk dependence $\left.\mathrm{P}(\mathrm{s} \backslash \mathrm{ter}(\mathrm{A} / / \mathrm{A}))=\mathrm{Y}(0) \exp ^{\wedge} \mid \mathrm{AjVs}_{\ln } \wedge^{\wedge}(\mathrm{a})\right)$ utility service 
from the confluence of event security circumstances ter (A/A) (combinations of values of I-security features) for each figurant involved $\mathrm{M}, \mathrm{B}, \mathrm{X}$ or $\mathrm{A}$ - the whole enterprise. On the Gibbs model of the set of I-events a normative identification of the HCS risk is based on the known normative values of the worst: $\mathrm{Y}(\mathrm{A} / \mathrm{A})$, the best: $\mathrm{Y}(0 / \mathrm{A})$ and the average risk: $\mathrm{YO} \bullet \mathrm{On}$ the horizontal axis are portfolio weight (relative to the HCS utility s) vs $(\mathrm{A} / \mathrm{A})=/ \mathrm{a} \mid \mathrm{Vs}, \mathrm{A}$, a, terraced I-events ter $(\mathrm{a} \mid \mathrm{A})$, arranged in ascending order. Under the horizontal axis in accordance with the values of the HCS risk "chess " designation of 64 average security conditions is given.
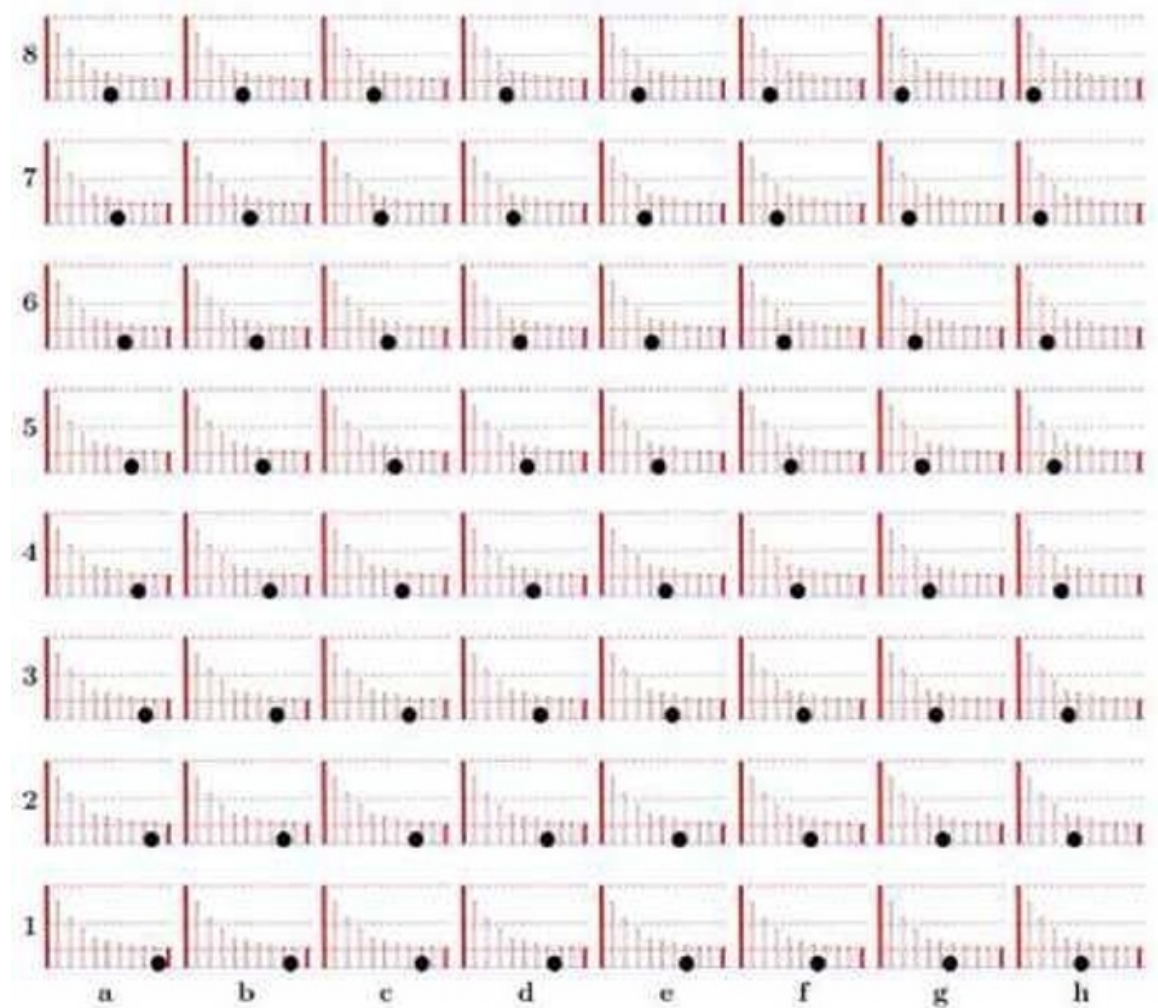

Figure 4. The Gibbs dependence risk of the HCS utilities of current average probable state of security of a typical enterprise. Black circles on the horizontal axis show the value of each of the 64 averageprobability security states, by which on the basis of the Gibbs event model the conditional probability of utility service is determined under the condition of the current security state. The safest state - a1, the least safe state - $\mathrm{h} 8$.

\section{Four stages of the HCS risk assessment by the HCS eventological system}

The procedure for assessing the current HCS utility risk of the enterprise by the HCS eventological system consists of four stages.

\subsection{Preparation of the optimal portfolio of $И$-signs}

Preparation of portfolio of I-signs must meet two criteria of optimality:

1. The portfolio of the HCS I-signs should provide admissible minimum expert costs for the examination of I-signs (see paragraph 4.5);

2. The accuracy of the risk assessment service on the basis of the portfolio of I-signs should be no worse than a specified level (see paragraph 4.6). 
Preparation of the optimal portfolio of I-signs is a solution to the eventological optimization problem, which optimizes the expert costs for examination of the portfolio Isigns, providing a given accuracy of the HCS risk assessment service (see paragraph 4.6); where the optimization of expert costs refers to the search for the optimal volume, structure (see paragraph 5) and information capacity of the portfolio of I-signs (see paragraph 4.5).

\subsection{Examination of l-signs}

Examination of I-signs from the optimally prepared portfolio consists in expert evaluation of binary values of I-signs: present or absent, according to the expert, this I-sign in the characteristic of the HCS current state.

\subsection{Identification of the HCS current state}

The results of the examination of I-signs from the optimally prepared portfolio serve as initial data for the identification of the HCS current state of the enterprise. The same standard algorithm [3, 4, 11, 12], based on the Gibbs event model (4.4.1) for a = M, B, or X, the identification of the current average probable state of each of the three figurants involved in the HCS is carried out (see Fig. 5 in paragraph 3): the total subject M, barrier B and object $\mathrm{X}$, thereby identifying the current average HCS state (see Fig. 1 in paragraph 3). Identification of the current state of the system is based on the same Gibbs event model (4.4.1) for $\mathrm{A}=\mathrm{M} U \mathrm{~B} U \mathrm{X}$.

\subsection{Calculation of the HCS utility}

On the basis of the Gibbs event model $[3,4,11,12]$ the risk - service of the HCS is offered on condition of the HCS current state ter (A//A) to be calculated by the formula:

$$
\left.\left(\mathrm{A} / /^{\mathbf{A}}\right)\right)=\mathrm{Y}(0) \exp \left(\mathrm{A}_{\mathrm{j}} \mathrm{V}_{\mathrm{s}}\right) \text { In, }
$$

where $\mathrm{Y}(0)$ is the worst risk, $\mathrm{Y}(\mathrm{A})$ is the best risk, $\mathrm{Yo}=\mathrm{P}(\mathrm{s})$ is the average HCS risk (see Fig. 6 in paragraph 3).

\subsection{Optimizing the expert costs for the I - signs portfolio examination}

To solve the problem of optimizing the expert costs for the I - signs portfolio examination the notion of a portfolio weight and an information capacity of I-sign are required.

Portfolio weight wa $=\mathrm{V}$ (a) of I-sign/I - of event a $€ \mathrm{~A}$ is determined on the basis of the Gibbs model, which relates it to the probability $\mathrm{P}=\mathrm{P}$ (a) of occurrence of И-event a $€$ by a known formula [1,9]

$$
\mathrm{RA}=\mathrm{Z} \exp \{\mathrm{a} w \mathrm{w}\}
$$

where a and $\mathrm{Z}$ are parameters of the Gibbs portfolio of I-signs.

The formula (4.5.1) allows to solve two mutually inverse probabilistic problems:

- by known portfolio weight wa of I-event a E A look for its probability px;

- according to the known probability pa of I-event a E X look for its portfolio weight

$$
\mathrm{Wa}=-\ln (\mathrm{paZ})
$$

as well as the problem of risk management service utilities with various restrictions on expert costs [16]. 


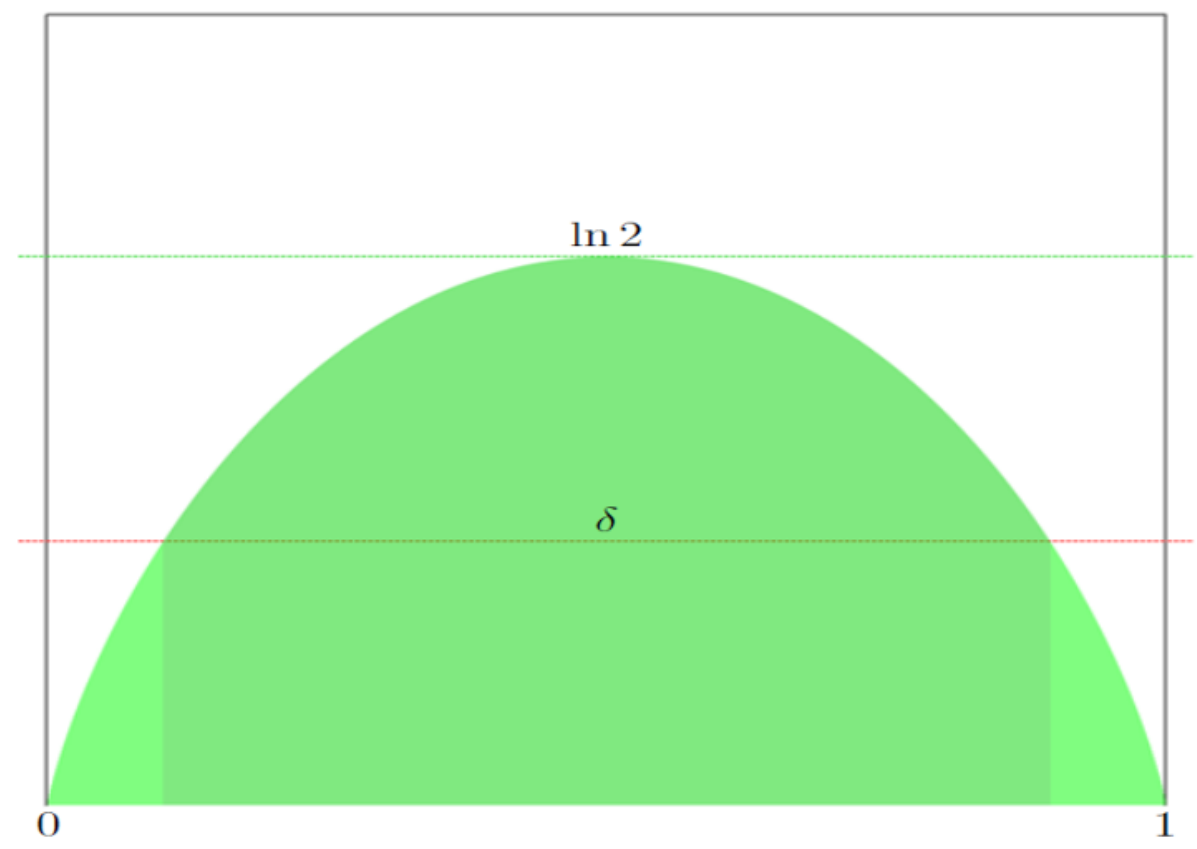

Figure 5. The unit square [1] 2 shows a subgraph (green) of the information capacity function Ia of the I - sign a depending on its probability pa (horizontal axis) (4.5.2), used for selection in the optimal expert portfolio of those features, the probability of which is not less than the threshold value 6 .

The information capacity of the I-sign / I-event is measured by the entropy of the I-event $\mathrm{x} € \mathrm{x}$ according to the known formula [1,9] (see Fig.5)

$$
\mathrm{Ia}=-\mathrm{RA} \ln \mathrm{RA}-(1-\mathrm{Pa}) \ln (1-\mathrm{RA}) \text {, }
$$

where $\mathrm{RA}=\mathrm{p}(\mathrm{a})-$ probability of the I-event $\mathrm{a} € \mathrm{~A}$

The interpretation of this information characteristic of an I-event is that if the probability of an I-event is close to 0 or 1 , then the expert verification of its occurrence gives little additional information, and its inclusion in the expert portfolio is not too justified. Selection criterion of I-sign $a € A$ from portfolio A in optimal export portfolio

$$
\mathrm{A}(\mathrm{e})(6)=\{\mathrm{a} € \mathrm{~A}: \mathrm{Ia}>6\} \text { With A, }
$$

is a significant value of its information capacity Ia, exceeding the threshold value of $6 €[0$, $\ln 2$ ], which is determined by the required accuracy of the HCS risk assessment utility.

\subsection{Optimizing the accuracy of performance evaluation}

The error e of the assessment of $\mathrm{p}(\mathrm{s})$ risk $\mathrm{P}(\mathrm{s} /$ ter $(\mathrm{A} / \mathrm{A})$ ) housing service $\mathrm{s}$ on the basis of the selected expert portfolio A (e) (6) can be calculated by the formula:

$$
\mathrm{a} £=\mathrm{M}-\mathrm{a}) / 2, \mathrm{~N}-1^{\wedge}=\text {, }
$$

where $\mathrm{t}(\mathrm{I}-\mathrm{a}) / 2, \mathrm{~N}-1-(1-\mathrm{a}) / 2$ is the Student's t-distribution quantile with $\mathrm{n}-1$ degree of freedom, $\mathrm{a}$ is the standard deviation, $\mathrm{a}$ is the required confidence level, usually taken as 0.95 , and $\mathrm{N}=|\mathrm{a}(\mathrm{e})(\mathfrak{f})|$ is the power of the expert portfolio, i.e. the number of $\mathrm{I}$ - signs included in $A(e)(S)$. Thus, the error£, which is the smaller the larger the square root of its power $N$, determines the confidence interval 


$$
\mathrm{JP}(\mathrm{s})-£<\mathrm{P}(\mathrm{s} \mid \operatorname{ter}(\mathrm{A} / / \mathrm{A}))<\mathrm{P}(\mathrm{s})+£,
$$

where the value of the risk of housing service falls with a probability of not less than a.

In addition to the power of the $\mathrm{n}$ export portfolio, the error of the $£$ risk assessment also significantly depends on the extent to which the relationship between the I - signs is characterized by this portfolio of selected I - signs. You can manage the interdependence and features in a portfolio by managing its event-probability structure. The principles of management of the event-probability structure of the export portfolio, which lead to a decrease in error, are set out in paragraph 5.

\section{Background: eventological model of expert portfolio of the HCS I-signs}

The key to the applicability of the eventological approach in the HCS field is the eventological model of the structure of the expert's answers to a set of regulatory HCS enterprises questions; in other words, - the structure of the expert portfolio of identification features/events (I-signs/I-events) of the enterprise.

Such event-probabilistic structure of the HCS I-signs should be organized in the optimum way so that at the minimum expert expenses to provide the required accuracy of risk assessment (probability) service of housing and communal services. It is theoretically clear that a large set of regulatory issues leads to greater accuracy of risk assessment. However, with the increase of this set, firstly, the costs of obtaining expert answers grow, secondly, the information capacity of the answer to each added question decreases.

Eventological model of I-signs portfolio

The HCS eventological model proposed in $[2,3,4,5,6,7,8]$ - is an event-based probabilistic model of the HCS enterprise, which is formed by the event interaction of three system total figurants, each of which is responsible for the event - related behavior of the corresponding totality: $\mathrm{M}$ - subjects, $\mathrm{B}$ - barriers and X-objects of the enterprise, joint event states of which form the event HCS state of the whole enterprise.

Table 1. Six sub-portfolios of I-events: Mi, M2, Bi, B2 and Xi, X2 forming the minimum complete portfolio $\mathrm{A}=\left\{\operatorname{ter}^{\wedge} / \mathrm{A}, \mathrm{A} \mathrm{C} \mathrm{A}\right\}$ from all possible (for portfolio A) 63 terraced $И$-events of the II kind generated by six medium-probability events (5.2.3) of their sextet $\mathrm{A}$ approximating $\mathrm{A}$ in the mediumprobability: $\mathrm{a}^{\wedge} \mathrm{A}$ (on the abbreviation $\mathrm{NN}, \ldots ., \mathrm{YYY}, \ldots, \mathrm{BBB}$ for subsets A C A. ${ }^{\text {ter }} \mathrm{A} / / \mathrm{a}=\Pi^{a \text { e A }}$ a G A

\begin{tabular}{|c|c|c|c|c|c|c|}
\hline а $M S$ A & $\mathrm{Mi}$ & M2 & $\mathrm{B} \mathrm{i}$ & B 2 & $\mathrm{Xi}$ & $\mathrm{X} 2$ \\
\hline ter_ $\mathrm{Y}$ & 0 & $\mathrm{O}$ & 0 & 0 & 0 & - \\
\hline ter-B & 0 & 0 & 0 & 0 & $\bullet$ & 0 \\
\hline ter $-\mathrm{H}$ & 0 & 0 & 0 & 0 & - & - \\
\hline ter_Y- & 0 & $\mathrm{O}$ & $\mathrm{O}$ & $\bullet$ & 0 & $\mathrm{O}$ \\
\hline ter.yY & 0 & 0 & 0 & - & 0 & - \\
\hline ter-YB & 0 & $\mathrm{O}$ & 0 & - & - & $\mathrm{O}$ \\
\hline ter-YH & 0 & 0 & 0 & - & - & - \\
\hline ter-в- & $\mathrm{O}$ & 0 & $\bullet$ & 0 & 0 & 0 \\
\hline ter-BY & 0 & 0 & - & 0 & 0 & - \\
\hline ter-вB & 0 & $\mathrm{O}$ & $\bullet$ & 0 & $\bullet$ & $\mathrm{O}$ \\
\hline ter-BH & 0 & 0 & - & 0 & - & - \\
\hline ter-H- & 0 & 0 & $\bullet$ & $\bullet$ & 0 & 0 \\
\hline ter-HY & 0 & 0 & - & - & 0 & - \\
\hline ter-HB & $\mathrm{O}$ & 0 & $\bullet$ & $\bullet$ & $\bullet$ & 0 \\
\hline ter-HH & 0 & $\mathrm{O}$ & - & - & - & - \\
\hline tery & 0 & • & 0 & 0 & 0 & 0 \\
\hline
\end{tabular}




\section{EECE-2018}

\begin{tabular}{|c|c|c|c|c|c|c|}
\hline${ }_{\mathrm{A}} M S_{\mathrm{A}}$ & $\mathrm{Mi}$ & M2 & B i & B 2 & $\mathrm{Xi}$ & $\mathrm{X} 2$ \\
\hline tery.y & 0 & - & 0 & 0 & 0 & • \\
\hline terY-в & 0 & • & 0 & 0 & • & 0 \\
\hline terY-H & 0 & • & 0 & 0 & • & • \\
\hline \begin{tabular}{|l|} 
teryY. \\
\end{tabular} & 0 & $\cdot$ & 0 & $\bullet$ & 0 & 0 \\
\hline $\operatorname{ter}_{\mathrm{YYY}}$ & 0 & $\bullet$ & 0 & • & 0 & $\bullet$ \\
\hline terYYB & 0 & $\cdot$ & 0 & $\cdot$ & • & 0 \\
\hline terYYH & 0 & $\cdot$ & 0 & $\cdot$ & $\cdot$ & $\bullet$ \\
\hline terYB- & 0 & $\bullet$ & • & 0 & 0 & 0 \\
\hline terYBY & 0 & $\bullet$ & $\cdot$ & 0 & 0 & - \\
\hline terYВв & 0 & $\cdot$ & $\bullet$ & 0 & $\cdot$ & 0 \\
\hline terYBH & 0 & $\cdot$ & $\bullet$ & 0 & $\cdot$ & • \\
\hline terYH- & 0 & $\cdot$ & $\bullet$ & $\bullet$ & 0 & 0 \\
\hline terYHY & 0 & • & $\bullet$ & $\cdot$ & 0 & $\cdot$ \\
\hline terYНв & 0 & • & $\bullet$ & - & • & 0 \\
\hline terYHH & 0 & • & • & • & - & $\bullet$ \\
\hline ters- & • & 0 & 0 & 0 & 0 & 0 \\
\hline ters-Y & • & 0 & 0 & 0 & 0 & • \\
\hline terв-B & $\cdot$ & 0 & 0 & 0 & • & 0 \\
\hline$t \mathrm{te}^{\wedge}-\mathrm{H}$ & $\cdot$ & 0 & 0 & 0 & $\cdot$ & $\bullet$ \\
\hline tersY- & $\cdot$ & 0 & 0 & $\cdot$ & 0 & 0 \\
\hline tersYY & $\bullet$ & 0 & 0 & $\cdot$ & 0 & • \\
\hline tersYB & - & 0 & 0 & - & - & 0 \\
\hline tersYH & - & 0 & 0 & - & • & • \\
\hline $\mathrm{te}^{\wedge}$ - & • & 0 & • & 0 & 0 & 0 \\
\hline terвsY & • & 0 & • & 0 & 0 & $\bullet$ \\
\hline terввв & - & 0 & • & 0 & • & 0 \\
\hline terввн & - & 0 & $\bullet$ & 0 & • & • \\
\hline terвH- & - & 0 & $\bullet$ & - & 0 & 0 \\
\hline te $e^{\wedge} \mathrm{HY}$ & $\cdot$ & 0 & - & • & 0 & - \\
\hline terвнв & $\cdot$ & 0 & $\bullet$ & $\bullet$ & $\bullet$ & 0 \\
\hline terвнн & - & 0 & $\bullet$ & - & $\cdot$ & $\bullet$ \\
\hline terH- & $\cdot$ & $\bullet$ & 0 & 0 & 0 & 0 \\
\hline terH-Y & $\bullet$ & $\bullet$ & 0 & 0 & 0 & $\bullet$ \\
\hline terH-в & $\bullet$ & $\cdot$ & 0 & 0 & $\bullet$ & 0 \\
\hline terH-H & - & - & 0 & 0 & - & - \\
\hline terHY- & $\cdot$ & - & 0 & $\cdot$ & 0 & 0 \\
\hline terHYY & $\cdot$ & $\cdot$ & 0 & $\cdot$ & 0 & • \\
\hline terнYB & $\cdot$ & $\bullet$ & 0 & $\cdot$ & $\bullet$ & 0 \\
\hline terHYH & - & - & 0 & - & • & - \\
\hline terнв- & - & - & - & 0 & 0 & 0 \\
\hline terнв Y & $\cdot$ & • & $\bullet$ & 0 & 0 & $\bullet$ \\
\hline terнвв & - & - & $\cdot$ & 0 & - & 0 \\
\hline ter^ $\mathrm{H}$ & - & $\bullet$ & $\bullet$ & 0 & $\cdot$ & $\bullet$ \\
\hline terHH- & $\cdot$ & $\bullet$ & $\bullet$ & $\bullet$ & 0 & 0 \\
\hline terHHY & $\bullet$ & $\bullet$ & $\bullet$ & $\cdot$ & 0 & $\bullet$ \\
\hline terннв & $\bullet$ & $\cdot$ & $\bullet$ & $\bullet$ & $\bullet$ & 0 \\
\hline terHHH & • & • & - & • & $\bullet$ & • \\
\hline
\end{tabular}

The HCS service utility eventological risk (probability) of the enterprise depends in which HCS event state the enterprise is. This event state is characterized by a portfolio of I-signs of the HCS of the enterprise, which usually consists of a set of expert answers to specially selected regulatory issues. The composition of the portfolio of I-signs and the organization of the event structure of these signs in the portfolio largely determine the accuracy of expert risk assessment and the amount of costs for the examination of the state of housing and communal services of the enterprise. 
The general structure of the portfolio of the HCS I-signs is determined by the hierarchical three-figurant structure of the HCS eventological model, where each of the three total figurants has its own two-multiple structure. This hierarchical structure is formed by three figurant portfolios of I-signs M, B, X, each of which is formed by the combination of two internal figurant sub-portfolios of I-signs:

$$
\mathrm{M}=\mathrm{Mi} \mathbf{U} \mathrm{M} 2, \mathrm{~B}=\mathrm{Bi} \mathbf{U} \mathrm{B} 2, \mathrm{X}=\mathrm{Xi} \mathbf{U} \mathrm{X} 2 .
$$

As a result, the structure of the entire portfolio of the HCS I-signs is characterized by a set of

$$
\text { A = Mi U M2 U Bi U B2 U Xi U X2, }
$$

which is formed by combining six figurant sub-portfolios of I-signs.

The task of choosing the optimal structure of the expert portfolio is reduced to the choice of six figurant expert sub-portfolios of I-signs (5.1.2), forming a common expert portfolio of I-signs of the enterprise $\mathrm{A}^{(\mathrm{e})} \mathrm{C} \mathrm{A}$, providing the required accuracy of the assessment of the minimum expert costs.

\subsection{Full expert portfolio of $И$-signs}

Table 1 illustrates the minimum total expert portfolio of I-signs, composed of combination of six sub-portfolios, each of which is defined by a corresponding subset of I- events

$$
\text { Mi, M2, Bi, В2, Xi и X2 C A. }
$$

This full expert portfolio A has a curious interpretation of the event which perhaps the only correct one when using the concept of certain average characteristics of the subsets of Ievents. The role of this average characteristic can successfully be performed, for example, by recently introduced concept of average-probability events [7, 15, 8, 16] in eventology]. In this interpretation, the entire expert portfolio is approximated by a set of only six averageprobabilities of I-events,

$$
\mathrm{Mi}, \mathrm{M} 2, B \mathrm{i}, B 2, \mathrm{Xi} \text { и X2 е A, }
$$

each of which approximates one of the six subsets of И-events (5.2.1), which, for example, for a subset of I-events Mi C A is interpreted as:

$\mathrm{Mi}=E(\mathrm{p} / \mathrm{Mi})=p \boldsymbol{M}_{l}$ e A.

If

$$
\mathrm{A}=\{\mathrm{Mi}, \mathrm{M} 2, B \mathrm{i}, B 2, \mathrm{Xi}, \mathrm{X} 2\} \mathrm{C} \mathrm{A}
$$

- the set composed as of elements of six average-probability I-events (5.2.3) approximating in the average-probability the entire expert portfolio A and for A C A generating $64=2^{6}$ terraced I-events of II kind of probabilities which form the probabilistic distribution of IIkind

$\{\mathrm{pA} / / \mathrm{a}, \mathrm{A}-\mathrm{a}\}$ sextet and-events a, where $\mathrm{PA} / / \mathrm{A}=\mathrm{P}(\mathrm{Tera} / / \mathrm{a}) \bullet$

Note 1. All events from the full portfolio A are collateral and are generated by six I - events of average probability of the sextet $\mathrm{A}$ as different results of terraced operations of the II-kind over sextet A, enumerated by its various subsets $\mathrm{A}-\mathrm{A}$.

Note 2. Table 1 uses an abbreviation for subsets of sextet A-A referring to the states of norms $(\mathrm{H})$, threat $(\mathrm{Y})$, recovery $(\mathrm{B})$ and efficiency $(\mathrm{O})$ of the HCS of each of the three HCS figurants involved according to the following rule. For an arbitrary figurant $\mathrm{F}=\mathrm{M}, \mathrm{B}$, or $\mathrm{X}$ approximated by the doublet of the average probable events $\{\mathrm{Fi}, \mathrm{F} 2\}$, its empty subset $0-$ $\{\mathrm{Fi}, \mathrm{F} 2\}$ corresponds to the average probable state of the HCS efficiency $(\mathrm{O})$, a subset $\{\mathrm{F} 1\}$ - to the average probable state of threat $(\mathrm{Y})$, a subset $\{\mathrm{F} 2\}$ - to the average probable state of recovery (B), and a subset $\{\mathrm{Fi}, \mathrm{F} 2\}$ - to the average probable state of the norm $(\mathrm{H})$.

Table 2. An example of completing figurants' sub-portfolios by I- signs in the minimal expert portfolio, which consists of six I - signs: 1,1,1,1,1,1, (from the top to the bottom). 
Abbreviation of subsets (see note 2 on page 113) is given, by which the corresponding Ievents are enumerated.

\begin{tabular}{|c|c|c|c|c|c|c|c|}
\hline \multirow{3}{*}{ I- signs } & \multirow{3}{*}{$\star \star \star$} & \multicolumn{6}{|c|}{ Sub-portfolio filling } \\
\hline & & \multicolumn{2}{|c|}{$0 \mathrm{~T}$} & \multicolumn{2}{|c|}{ OT } & \multirow[b]{2}{*}{$x_{1}$} & \multirow[b]{2}{*}{$\mathrm{x}_{2}$} \\
\hline & & OT $i$ & от 2 & $\mathrm{OT}_{\mathrm{i}}$ & от 2 & & \\
\hline O- object counteraction & $\mathrm{Y}$ & - & . & - & . & - & . \\
\hline O- object stability & $\mathrm{B}$ & & & & & $\cdot$ & \\
\hline 0- barrier counteraction & $-Y-$ & & & & . & & \\
\hline O- barrier stability & $-\mathrm{B}-$ & - & . & - & - & - & - \\
\hline O- subject counteraction & $Y$ & - & • & - & . & - & . \\
\hline O- subject stability & $\mathrm{B}$ & . & & & & & \\
\hline
\end{tabular}

Therefore, for example, the abbreviation "-YH" corresponds to the HCS average probable state, when the total subject $\mathrm{M}$ is in an arbitrary average probable state, the total service $\mathrm{B}$ is in the average probable state of threat $(\mathrm{Y})$, and the total object $\mathrm{X}$ is in the average probable state of norm $(\mathrm{H})$. Examples of the use of abbreviations:

\begin{tabular}{|c|c|c|}
\hline ter- & -- & $={ }^{\operatorname{ter}} 0 / / \mathrm{a}$, \\
\hline ter-Y. & $={ }^{\text {ter }}\left\{*_{\mathrm{B}} 2\right\} / \mathrm{a}$, & \\
\hline ter-YH = & ter & $\{\mathrm{B} 2, \mathrm{Xi}, \mathrm{X} 2\} / \mathrm{a}$ \\
\hline ter-BH = & ter & $\{\mathrm{S} \mathrm{i,X} 1$ Д2 2$\} / \mathrm{a}$ \\
\hline${ }^{\operatorname{ter}} \mathbf{Y}-\mathbf{Y}$ & ter $\{\mathbf{M} 2, \mathbf{x} 2\} / \mathbf{a}>$ & \\
\hline ter $\mathrm{HHH}$ & & $={ }^{\operatorname{ter}} \mathrm{a} / / \mathrm{a} \cdot$ \\
\hline
\end{tabular}

Terraced is such a set-theoretic operation on a set of events, the result of which is the terraced event of one of the six standard types [1,9], generated by this set of events.

The results of terraced operations of II-kind on the events of A are terraced events of IIkind ter $(\mathrm{A} / \mathrm{A})=\mathrm{P}^{\prime} 1 \mathrm{ASP}$, numbered by subsets of A C A.

\subsection{Minimum expert portfolio of I-signs}

Minimum expert portfolio of I-signs (see Tab. 2) although it allows to solve all the problems facing the HCS eventological system, does not guarantee the required accuracy of risk assessment.

\subsection{The minimum weighted expert portfolio of I-signs}

The minimum weighted expert portfolio of I - signs (see Tab. 3) also allows you to solve all the problems facing the HCS, it can provide the required accuracy of risk assessment by varying the weights of I-signs in the portfolio, but does not have the ability to take into account the relationships of I-signs in the portfolio.

\subsection{An Arbitrary expert portfolio of I-signs}

An arbitrary expert portfolio of I-signs, containing a weighted minimum portfolio, allows to solve all the problems facing the HCS eventological system, can provide the required accuracy of risk assessment, and has the ability to take into account the relationships of Isigns in the portfolio with the help of I-signs contained in more than one sub-portfolio out of six.

It is possible to take into account all kinds of relationships between I-signs in the portfolio using a weighted full portfolio of I-signs of the HCS, corresponding to all possible terraced events of the II kind, generated by the corresponding average probable expert portfolio, which consists of 38 I-signs corresponding to 6 terraced I-events of the II kind with weights. 
Each pair of internal figurant sub-portfolios of I- signs is required, mainly, in order to assess, in what state out of the 4- cycle states of the HCS (norm, threat, discomfort, recovery) is each of the three figurants, and, consequently, in what state out of 64 the entire system of housing and communal services of the enterprise is. In addition, the internal figurants' subportfolios of I-signs can be used to assess the private risks of the utility service for each figurant individually, or for each of the pair of parties of the figurant separately.

\section{References}

1. O.Yu. Vorobiev, Eventology, Siberian Federal University, Krasnoyarsk (2007)

2. S.P. Amelchugov, Yu.A. Andreev, S.Yu. Komarov, Assessment of forest fire safety, Proceedings of the conference on financial and actuarial mathematics and eventology of housing and communal services, Siberian Federal University, 33-38 (2011)

3. S.P. Amelchugov, I.A.Bolodian, G.V. Bokov. Fire safety on the territory of the Russian Federation, M. VNIIPO, 462 (2006)

4. Technical regulations on the safety of buildings and structures Federal law of 30.12.2009 № 384-FZ. M: Morkniga, 31 (2018)

5. Technical regulations on fire safety requirements: Federal law No. 123-FZ of 22.07.2008. M. VNIIPO, 148 (2012)

4 S.A. Sokolova, K.V Borisova. Problems of housing and communal services as an indicator of the state of society. Fundamental research 11-4, 870-874 (2016)

6. L.P.Yagodina Management of housing and communal services: organizational and legal aspects, (2012)

7. S.B. Sivaev, How to effectively manage the housing stock, Economy housing and public utilities, 5 (2002)

8. S.P. Amelchugov, S.V. Klochkov, New information technologies in fire safety, Fire safety, 3, 144-151 (2015)

9. I.S. Inzhutov, V.I. Zhadanov, D.A. Ukrainchenko, A.F. Rozhkov, V.E. Afanasiev, Methodological foundations of the search for rational solutions in wood panel designs, Orenburg-Krasnoyarsk: LLC IPK "University", 295, (2016)

10. G.F. Sheshko, Comment to the Housing code of the Russian Federation, M.: Law Company "CONTRACT", (2011)

11. V.I. Vasiliev, Municipal law of Russia: "Justicinform" (2012)

12. V.B. Zotov, The system of municipal management: Textbook for universities, St. Petersburg, 512 (2008)

13. The standard of living and the problems of housing and communal services are more important than democracy and human rights, Press issue 1902 (2011)

14. E.E. Goryachenko Condition, utilities and amenities: expert survey, Budget, 2 (2011)

15. O.V.Nurullina, Economy, business and law. 11, 12-19 (2019).

16. G.A.Emelyanova, Some aspects of organizational and economic development of mechanisms of reforming housing and communal services of the region, Russian entrepreneurship, 2, 178-183 (2011) — http://www.creativeconomy.ru/articles/14338/.

17. A.V. Malyshev, D.A. Glazov, A.V. Volotka, I.I. Tupitsyn, V.M. Shabaev, G. Plunien, T. Stöhlker, Ground-state ionization energies of boronlike ions, Phys. Rev. A (2017) 96 (2).

18. O.M. Zhigalina, A.A. Semenov, A.V. Zabrodin, D.N. Khmelenin, D.A. Brylev, A.V. Lizunov, A.L. Nebera, I.A. Morozov, A.S. Anikin, A.S. Orekhov, A.N. Kuskova, V.V. Mishin, A.V. Seryogin, Crystallogr. Rep. 61 (4), 549-557 (2016)

19. R. Usmanov, N. Vatin, V. Murgul, Appl. Mech. Mater. 633-634, pp. 1082-1085. (2014)

20. O.P. Minaev, Packing Power Technol. Eng. 52 (2), pp. 128-134 (2018)

21. K.S. Fahmi, M.Y. Fattah, A. Pustovgar, MATEC Web Conf. 170 (2018)

22. O.G. Rumba, J.R. Nigmatulina, Teoriya i Praktika Fizicheskoy Kultury (2016). 